\title{
Brief Analysis on Characteristics of Army NCO Education and Teacher Teams Con- struction under New Situation
}

\author{
Qiangye Gao ${ }^{1}$ \\ ${ }^{1}$ Dept. of Equipment Support, Bengbu Automobile NCO Academy, Bengbu 233011, \\ China, gaoqiangye@gmail.com
}

\begin{abstract}
The vocational education of army noncommissioned officer (NCO) has been the inevitable trend of the development of military vocational education recently. In this paper, the basic characteristics of the vocational education of Army NCO are summarized firstly. Then the basic qualities that the teachers of army NCO colleges should have are clarified in detail. At last, several suggestions on how to strengthen teacher teams of army $\mathrm{NCO}$ colleges are proposed.
\end{abstract}

Keywords: Non-commissioned officer (NCO); Vocational education; Teacher teams; Quality

\section{Introduction}

The Sixteenth Army College Work Conference follows the guidance of a series of important statements of Chairman $\mathrm{Hu}$ about army college education and military talents training and the major strategic thoughts centering round accelerating fighting capacity pattern transformation, and further perfects the new military talent training system which takes vocational education as a main line, integrates army college education and national education and combines army colleges with training agencies. Meanwhile, with the rapid development of modern science and technology, new patterns of arms and ar- maments emerge in large numbers and their scientific and technological contents have also been greatly enhanced. Therefore, the vocational education of the noncommissioned officers (NCO) will definitely become a major trend in military education and will see more superior development opportunities and greater development space. As the initiators of knowledge and skills for NCO students, the organizers of teaching activities and the enlighteners of thought, teachers play an essential role in the vocational education of NCOs. Hence, the strengthening of teacher team construction of army NCO colleges and the establishing of a competent and qualified teacher teams become especially important. Therefore, we should mainly ponder over the issue of how to purposefully improve the comprehensive qualities of teacher teams and strengthen teacher team construction according to the characteristics of NCO vocational education.

\section{Basic Characteristics of Army NCO Vocational Education}

\subsection{Military Education}

It is beyond question that NCO education is an important part of military education and it constitutes the whole military education together with other military educational forms, like officer education. Therefore, NCO education also has the 
common characteristic of military education, namely, being of military significance. That is to say, NCO education serves the army and is featured by military attributes, and thus, its education forms, contents, organization and management should all abide by the basic laws and requirements of military education.

\subsection{Vocational Education}

Vocational education refers to the kind of education that is able to render students the knowledge and skills needed to be engaged in certain productive labor. NCO education is exactly an education that can give NCO students the knowledge and skills required for taking part in certain vocational work for a long time. In addition, it can also educate students on vocational ethics and moral principles, such as taking root in the grass roots, loving one's work, being passionate in one's job and voluntarily devoting oneself for others, as required by the occupation of noncommissioned officers. Thus it can be seen that the NCO education has the typical features of vocational education. It can be said that NCO education is the expansion of vocational education in the military field, or it is the vocational education in modern military field [1]. Hence, $\mathrm{NCO}$ education is bound to be governed and restrained by the general laws of vocational education.

\subsection{Post Directionality}

The NCO education focuses on knowledge and skill required by posts, and is geared directly to or intends to satisfy the needs of the post or rank promotion. It is of directionality either in student recruitment or allocation, or in the establishment of education objectives and courses [1]. Therefore, the NCO education must be oriented toward the needs of the army to determine training targets, course structures allocated, course knowledge points installed and technical skill programs.

\subsection{Multi-hierarchical Training Pat- terns}

The new NCO system categorizes noncommissioned officers into primary, medium and advanced ones which require different post capacities and responsibilities for the NCOs, and selects and promotes officers level by level. According to the Overall Army Non-Commissioned Officer Training Plan, in order to put the NCO promotion principle of "no training, no promoting" into practice, we must be change the single training pattern, formulate a multi-layer training model and install corresponding educational systems according to the ranks of the NCOs [1].

\section{Qualities Required for Teachers in NCO Colleges}

\section{1. “Double Functional" Qualities}

The National Medium-and-Long-Term Educational Reform and Development Plan (2010-2020) has explicitly proposed to strengthen the construction of "double functional" teacher teams. As a typical military vocational education, the NCO education in the army has also brought forward the requirement of constructing "double functional" teacher teams in faculty team construction [2]. However, because of the military characteristics of the NCO colleges, the meaning of a "double functional" teacher there also differ from that of local vocational colleges, since he must be the combination of a soldier, teacher and engineer. The "double functional" teachers in the NCO colleges should be equipped with the following qualities: excellent military qualities, solid basic military theories and education theories, and superior teaching abilities. He must have solid vocational theoretical 
knowledge and great practicing ability, have good knowledge about new knowledge, theories, techniques and equipments applied in actual work of the army, and have the ability to lecture vocational military courses as well as instruct vocational military skill training.

\subsection{Academic Research Ability}

In order to guarantee the constant improvement of teaching levels of teachers, they should also be possessed with certain degree of academic research ability. The academic research ability and teaching ability is two aspects that can reflect the teaching capability of a teacher, though the two is actually a unified entirety. Only through academic research activities can teachers update their intellectual reserve timely and achieve the integration of theory and practice. This kind of scientific practice, in turn, will further the theoretical levels of teachers and promote the constant enhancement of teaching levels.

\section{3. "3C" Spirits}

Teachers in NCO colleges should be required to establish a "3C" spirit, namely, "Conscientiousness, confidence and constancy". First of all, teachers should have strong "conscientiousness", love their job, face up to the fact that the NCO students generally have a poor culture base, show highly responsible attitude, inspire their enthusiasm in teaching and devote themselves wholeheartedly to teaching. Meanwhile, they have to possess "confidence", believing that they have the ability to improve the study of their students, and make different teaching measures according to the actual conditions of different students instead of complaining. In addition, they have to have "constancy" as well. Maybe the great efforts of the teachers could not bring them returns immediately. But instead of being dis- couraged, they should keep their resolve, make greater efforts, and instruct students patiently.

\section{Suggestions on Strengthening Teacher Teams Construction}

In order to realize normalized teaching, improve teaching quality and foster highquality NCO talents, a teacher team that has high theoretical level, great practicing ability, reasonable knowledge structure, certain academic research ability and " $3 \mathrm{C}$ " spirits must be constructed as a guarantee. To make this objective come true, efforts should be made from the following aspects [3-5].

\subsection{Greatly Strengthening the Train- ing of In-service Teachers}

Various measures centering round inservice training and being supported by advanced studies should be adopted to train teachers. Aimed at the characteristics of NCO education, we should emphasize the construction of "doublefunctional" teacher teams, especially strengthening the training of practical operational capacity of teachers, and conduct new equipment operation training in rotation for teachers at irregular intervals. By the method of bringing in and walking out, we should organize teachers to learn knowledge about new equipment, enable them to master the principle, operation, technical malfunction and tactical application of new equipment and make new equipment have teaching functions. Meanwhile, we should organize teachers to practice in army at regular intervals, and allow them to collect information about new equipment and facilities used in the army at present, difficulties in using these equipment and facilities and teaching contents lagging behind the development of army equipment. In this way, it can bring NCO teaching closer to 
the reality of army equipment and improve the teaching quality.

\subsection{Putting People First and Respect- ing Teachers and Their Teaching}

The NCO colleges should establish the concept of putting people first, bring teacher team construction to the center of college construction, and emphasize cultivating talents with career, encouraging talents with policies and retaining people talents with environment. They should persisting in the central status of teaching, advocate the tradition of respecting teachers and their teaching and build a favorable environment for talent development. Meanwhile, relevant departments should make integrated planning and reasonable arrangement, and integrate resources to build a platform for teachers to display their talents.

\subsection{Establishing Impartial Evaluation Mechanism}

An objective and impartial evaluation mechanism can stimulate the constant appearance of excellent talents. The evaluation should insist on "sunlight working", focusing on making the evaluation mechanism democratic and open. As to the methods of evaluation, we should combine qualitative and quantitative methods together, and highlighting quantized assessment, adopt various forms, such as quantized grading, inquiry, hearing of witnesses and accountability, to give the evaluating right to the basic level in the real sense. In the contents of evaluation, we should stick to the organic unification of virtue and talent to avoid onesidedness. With regard to the usage of evaluation results, we should both focus on assistance and connect them to talent exploitation to bring the evaluation benefits into play.

\subsection{Actively Encouraging Teachers to Conduct Academic Research Ac- tivities}

Academic research is an important way of enhancing teacher team construction. High-quality academic research activities can greatly increase the knowledge reserve of teachers and elevate teaching quality. Teaching must be combined with academic research in order to keep pace with the times and enter into a higher level. Only academic research can enable teachers to learn about new scientific and technological achievements in time, keep up with the new pace of scientific and technological development, constantly enrich and update teaching contents and improve the quality and level of NCO education.

\section{References}

[1] Y. Qi, "Analysis of the basic characteristics of our army NCO education in the new century," Research Magazine of Chinese Basic Education, vol. 6, pp. 126-127, 2010.

[2] X. D. Xue, X. D. Chen, and B. Xu, "Thinking about teaching mode innovation of NCO education," New Curriculum Research, vol. 1, pp. 120-121, 2012.

[3] L. Li, F. Guo, and X. A. Wang, "How to strengthen the procession of teachers on new position," Science \& Technology Information, vol. 3, pp. 179-180, 2008.

[4] L. D. Chen and K. K. Chen, "Study on the teacher team construction of vocational education," Adult Education, vol. 2, pp. 38-39, 2012.

[5] H. Q. Lai, J. J. Song, and W. J. He, "Exploration and analysis of teacher cultivation mode of vocational education," Heilongjiang Researches on Higher Education, vol. 1, pp. 77-80, 2012. 